\title{
Cuando los videojuegos escribieron el Holocausto: análisis de Wolfenstein: The New Order (Machinegames, 2014)
}

\author{
Aarón RodríGuez SERRANO \\ Universidad Europea de Valencia \\ aaron_stauff@hotmail.com
}

Recibido: 10 de julio de 2014

Aceptado: 19 de septiembre de 2014

\begin{abstract}
Resumen
El artículo pretende ser un análisis de Wolfenstein: The New Order (Machinegames, 2014), el primer videojuego en construir una narración que incorpora de manera explícita distintos contenidos relacionados con el Holocausto Se pretenden evaluar de manera crítica los distintos elementos que generan significación dentro del videojuego, utilizando para ello tanto un enfoque estético (construcción visual, narratividad) como ético (posibilidades y límites de la representación del Holocausto). Para ello, optaremos por una doble metodología de análisis formal y temático, heredera de los procesos de análisis fílmico holocáustico pero convenientemente adaptada al lenguaje del videojuego. El trabajo resultará pionero no sólo por la cercanía con el objeto de estudio, sino por la propia necesidad que éste exige a la hora de adaptar las herramientas analíticas ya establecidas en los procesos de significación de la representación holocáustica a un formato polémico y nunca antes utilizado con estos fines.
\end{abstract}

Palabras clave: Holocausto; Videojuegos; Wolfenstein: The new order; Análisis textual.

\section{When the videogames wrote the Holocaust: analysing Wolfenstein: The New Order (Machinegames, 2014)}

\begin{abstract}
Our paper tries to propose an analyse of Wolfenstein: The new order (Machinegames, 2004), the first videogame who shows explicitly several representations of the Holocaust. We will evaluate critically the different elements who create meaning in an aesthetical level (visual construction, narrative aspects) and an ethical level (possibilities and limits of the Holocaust's representations). Methodology: We will use a mixed methodology based on the formal and narrative levels, adapting the classical theories about the representation of the Holocaust into the videogames 'code. Results: The work will be pioneering not only for the newness of the object of study, but for the adaptation to the classical analytical tools about the Holocaust in a polemic and new format, never used before with those intentions.
\end{abstract}

Key words: Holocaust; Videogames; Wolfenstein: The new order; Textual Analyse.

\section{Referencia normalizada}

Rodríguez Serrano, A. (2014) Cuando los videojuegos escribieron el Holocausto: análisis de Wolfenstein: The New Order (Machinegames, 2014). Historia y Comunicación Social. Vol. 19. Páginas 193-207.

Sumario del artículo: 1. Introducción. 2. Metodología. 3. Resultados y discusión. 3.1. Aspectos formales. 3.1.1. Una construcción postmoderna. 3.1.2. Construcción del punto de vista y personaje principal. 3.1.3. Gestión del espacio y el tiempo. 3.2. Aspectos éticos. 3.2.1. Los cuerpos imperfectos: La mostración de las políticas de eugenesia. 3.2.2. El exterminio racial. 4. Conclusiones. 5. Referencias bibliográficas 


\section{Introducción}

El pasado 23 de Mayo de 2014 la distribuidora Bethesda Software ponía a la venta la última entrega de la célebre saga de videojuegos Wolfenstein. Desde que en 1981 la compañía Muse Software lanzara su original Castle Wolfenstein, la saga ha mantenido diversas relaciones críticas con la comunidad académica. Generalmente acusada por su alto contenido violento (E. Dill y C. Dill, 1998; L. Carnagey \& A. Anderson, 2004: 2; P. Barlett, J. Harris y Baldassaro, 2007: 488), o ignorada en los trabajos en torno a las relaciones entre segunda guerra mundial, aprendizaje y videojuegos (Fisher, 2011; R. Watson, J. Mong \& A. Harris, 2011), los productos vinculados con la franquicia apenas han contado hasta el momento con análisis monográficos que escaparan de lo puramente anecdótico y se centraran en el análisis concreto de sus procesos de significación.

E incluso más allá de ese incómodo silencio en torno a una colección que a fecha de hoy engloba al menos nueve entregas oficiales para casi una veintena de plataformas -del primer Apple II a la recién estrenada Playstation 4- o más allá del innegable fenómeno social que se ha generado en torno a las comunidades de pequeños desarrolladores que han generado miles de mods (expansiones amateurs realizadas sin ánimo de lucro y distribuidas por internet que se valen del código original para expandir el universo del videojuego), hay un dato capital que exige un análisis desde la academia. Wolfenstein: The New Order, hasta el momento su última entrega, introduce por primera vez elementos relacionados con el Holocausto en la construcción visual y narrativa de un videojuego.

Como ya se ha estudiado en otros lugares (Frasca, 2004; Rodríguez Serrano, 2014), las relaciones entre Holocausto y videojuegos siempre se han mantenido en sordina. A la ya habitual incomodidad que los parámetros de la representación han ido implicando en las reflexiones en torno a la mostración visual del Holocausto tema al que volveremos en unas páginas-, habría que añadir además la problemática propia de otros parámetros intrínsecamente conectados con el mundo del videojuego: la interactividad, la concepción quebrada y repetitiva del tiempo y el espacio, los flujos de empatía y personalización... Los videojuegos cuentan con su propia retórica política e ideológica (Bogost, 2007: 67-120), y pese a su ya indudable estatuto como arte del siglo XXI, todavía pende sobre ellos la percepción de la banalización, la puerilidad, o simplemente, su naturaleza puramente mercadotécnica. Rasgos ellos, en principio, diametralmente opuestos a lo esperable en los mecanismos de recuerdo del Holocausto.

Durante las siguientes páginas, pretenderemos ofrecer una lectura concreta de Wolfenstein: The New Order que no se apoye únicamente en los tópicos sobre la inefabilidad de lo ocurrido en los campos, sino que considere el videojuego como un producto cultural que, en tanto texto, configura subjetividades y genera la posibilidad de una lectura estética, ética y -en el caso concreto que nos ocupa- directamente relacionada con la Historia. 


\section{Metodología}

Los estudios sobre las representaciones del Holocausto han experimentado en las últimas dos décadas una serie de cambios que merece la pena señalar como fundamento metodológico de nuestro trabajo. Si bien la escuela de la inefabilidad -aquella para la que el holocausto es necesariamente irrepresentable, excede los límites de la creación artística e incluso del pensamiento mismo- fue propuesta en primer lugar por los supervivientes (Wiesel, 1985) y después recogida por diferentes teóricos nacionales e internacionales (Sánchez-Biosca, 2001; Wajcman, 2001; Reyes Mate, 2003), de un tiempo a esta parte se ha propuesto una notable modificación en nuestra manera de entender las escrituras del trauma holocáustico. Así, por ejemplo, los trabajos de Marianne Hirsch $(2001,2008)$ o de Dora Apel (2002) han intentado legitimar la representación mediante la llamada "postmemoria" como una responsabilidad global en la que los descendientes de los supervivientes y otros sujetos han utilizado los mecanismos artísticos para constituir una suerte de comunidad reflexiva sobre la herencia del Holocausto. Del mismo modo, se ha reivindicado la posibilidad de un "decir holocáustico" desde campos tan dispares como el montaje audiovisual (Didi-Huberman, 2013), los estudios cognitivos de la imagen (Kerner, 2011), el arte contemporáneo (Bennett, 2005), la reflexión política más crítica (Finkelstein, 2014) o incluso la propia historiografía del Holocausto (Bauer, 2002; Rodríguez Serrano, 2013). Quizá nadie ha sintetizado nuestra posición con tanta claridad como el filósofo Jacques Rancière cuando afirmó que el Holocausto "no plantea más que problemas de irrepresentabilidad relativa, de adaptación a los medios, y de los fines de la representación" (2011: 131).

Sólo partiendo de esta base podemos justificar nuestra aproximación metodológica a Wolfenstein: The New Order desde una perspectiva libre de prejuicios y no deudora de los lugares comunes en torno a la hipotética banalización que supone representar (sea del modo que sea: pictórico, cinematográfico, escultórico, arquitectónico o memorialístico...) la experiencia holocáustica. Siguiendo a Rancière, nuestro objetivo bien podría ser la detección de esos problemas de "irrepresentabilidad relativa", de la manera en la que un videojuego impone su "adaptación a los medios", y por supuesto, de los consecuentes "fines de la representación" ideológicos.

Para conseguir estos objetivos utilizaremos una metodología de análisis mixta, no tan preocupada por los modelos de análisis de parámetros como la jugabilidad (González, Gutiérrez, Montero y Padilla-Zea, 2012) sino entendiendo el videojuego desde dos perspectivas distintas. En primer lugar, como un texto productor de sentido (Frasca, 2009; A. Paul, 2012), dotado de herramientas estéticas propias (Egenfeldt-Nielsen, Heide y Pajares, 2013: 117-156, 2009) que generan una significación concreta y que dependen de una tradición icónica y expresiva puramente postmoderna. En segundo lugar, como un texto ideológico (Squire, 2006) capaz de generar complejos dilemas éticos (Zagal, 2009), que se relaciona de manera explícita con la creación de subjetividades y sensibilidades políticas (Siabra, 2012: 147-171). Obviamente, ambas dimensiones de la experiencia textual están íntimamente conectadas 
y, como ya sabemos gracias a la experiencia de distintas metodologías de análisis fílmico, la forma misma es constructora de implicaciones ideológicas (Zumalde, 2011). Nuestra intención es respetar ambos terrenos de la lectura, pero en ningún caso escindirlos o convertirlos en compartimentos estancos.

\section{Resultados y discusión}

\subsection{Aspectos formales}

\subsubsection{Una construcción postmoderna}

El videojuego puede ser considerado, sin duda alguna, como la manifestación artística postmoderna por excelencia: propone una torsión de las tramas directamente heredada del folletín (Calabrese, 2012), combina sin ningún pudor los elementos de la alta y de la baja cultura (Clarke y Mitchell, 2007: 9), y sobre todo, acepta en sus relaciones con la Historia un margen amplio de relatividad que tiene más que ver con la cita o el pastiche que con el rigor documental. Sin intentar minimizar el interés de los llamados "videojuegos educativos" (González-González y Blanco-Izquierdo, 2012), en general las fuentes literarias y fílmicas de las que beben las diégesis virtuales suelen estar mucho más vinculadas al género fantástico, la Serie B o la historia contrafactual. Esto ha dado lugar a una interesante paradoja expuesta por Harry J. Brown:

Los videojuegos han forzado a los historiadores a escrutar con la mayor severidad posible a su propia disciplina. Mientras que imponen (...) severas restricciones éticas a la manera de mostrar el pasado, también representan una poderosa innovación pedagógica por su habilidad específica a la hora de generar empatía y considerar los eventos históricos desde diferentes puntos de vista (2008:118-119).

Estos tres rasgos, sin duda, configuran el punto de partida de la diégesis de The New Order. Al igual que ocurría en obras literarias como El hombre en el castillo (K. Dick, 2010), el universo temático que arropa el juego parte de la premisa de una hipotética victoria del ejército alemán en la II Guerra Mundial. A su vez, la escisión del juego en aproximadamente quince episodios temáticos conectados entre sí y separados por escenas cinemáticas (Gómez Tarín, 2012) refleja una curva microestructural lineal que respeta escrupulosamente las estructuras del guion cinematográfico de aventuras (Sánchez-Escalonilla, 2009), incluyendo rasgos propios del género como la incorporación de Cliffhangers o escenas que dejan al jugador en suspenso para invitarle a continuar jugando.

Es importante recordar, por lo tanto, que The New Order no pretende realizar una lectura exhaustiva de los elementos históricos, sino antes bien, generar una torsión sobre ellos para invitarnos a buscar nuevos significados en nuestra percepción de los mismos. Así, podemos encontrar una suerte de meta-reflexión sobre los elementos 
que componen la propia construcción lúdica: las paredes están decoradas por posters que remiten tanto a La mujer en la luna (Frau im Mond, Fritz Lang, 1929) como a Ilsa, la loba de las SS (Ilsa: She Wolf of the SS, Don Edmonds, 1975), la banda sonora incorpora referencias a Wagner, a Emmanuel d'Astier/Anna Marly/Leonard Cohen (los tresillos iniciales de algunos de los temas apuntan a La complainte du Partisan/ The partisan) o a Jimi Hendrix y su interpretación del himno norteamericano. Del mismo modo, los programadores han incorporado capturas de pantalla del Wolfenstein $3 D$ original (iD Software, 1992) para decorar la guarida de los miembros de la resistencia o los ordenadores de la base lunar. Se trata, por lo tanto, de un tapiz de fragmentos arrancados de todo el siglo XX, reordenados y reubicados en una nueva cadena significante. Ahora bien, no debemos perder de vista que entre todos los referentes icónicos, los programadores han decidido incorporar también el Holocausto. Este es, precisamente, el punto de inflexión que motiva nuestro trabajo. Volveremos sobre esta idea.

\subsubsection{Construcción del punto de vista y personaje principal}

Siguiendo las teorías sobre el punto de vista propuestas por Gómez Tarín, Rubio Alcover y Tomás Samit, el jugador de The new order queda directamente vinculado empáticamente al personaje principal, el sargento B.J. Blazkowicz, gracias a una serie de recursos entre los que destacamos para nuestro análisis: "La impresión de realidad, que en los videojuegos no tiene entidad alguna ni tiene por qué darse, ya que el jugador es plenamente consciente del universo en que ejecuta sus comandos, sea cual sea la calidad gráfica, incluso si esta es hiperrealista" (2012: 9). Este rasgo, que compartimos plenamente con los autores, nos lleva a la siguiente conclusión: esta conciencia del punto de vista no sólo permite la quiebra con la Historia, sino que además garantiza una distancia crítica que permite un amplio margen de reflexión sobre lo expuesto. The new order, a diferencia de otros juegos de acción, apoya directamente todo el sentido de las acciones en una idea política principal (la oposición activa contra los totalitarismos), de la que a su vez se desprende una serie de ideas secundarias (el respeto a la existencia de colectivos ajenos al propio, los límites en las conexiones entre progreso e inhumanidad...) de los que nos ocuparemos posteriormente. Por el momento, baste con señalar que el punto de vista formal juega con una especie de doblez representativo: inmersión en el protagonista en las escenas de acción y en la toma de decisiones directa sobre la historia (mediante la construcción de la mirada en primera persona y la interacción [Delgado y Granados, 2012: 68-69]), distancia del mismo en las escenas cinemáticas en las que se despliegan su sueños, sus recuerdos o su crecimiento emocional como personaje. Esta doble naturaleza inmersión/distancia no sólo muestra a las claras las estrategias de la enunciación (González Hortigüela, 2009), sino que permite al sujeto una suerte de recorrido flotante sobre los acontecimientos.

Siguiendo con el sistema analítico propuesto por Gómez Tarín, Alcover y Samit, el Sargento B.J. Blazkowicz es el único personaje que funciona como avatar en todo The new order, y en torno a él se gestionan todos los recursos de ocularización y 
auricularización -implícita durante el juego, omnisciente durante las secuencias cinemáticas. Sobre él, se despliega un Meganarrador que interviene como instancia narradora en ciertas ocasiones mediante el uso de un segundo narrador de primer nivel -el propio Blazkowicz- que se manifiesta en la voz en off que escuchamos en ocasiones. Las funciones de este recurso van siempre destinadas a reforzar los mecanismos empáticos: recuerdos de otras batallas, sueños truncados por la guerra, proyección de un hipotético futuro con la mujer amada... Una vez más, se trata de lugares narrativos comunes dados por el género bélico, más cercanos al serial o al folletín.

Hay, sin embargo, una muy interesante quiebra de los mecanismos del punto de vista en el final mismo del juego. Tras el enfrentamiento con el último villano, el protagonista sufre un ataque sorpresa que le lleva hasta el umbral mismo de la muerte en el que, para colmo, autoriza un ataque nuclear sobre la zona en la que se encuentra. Sin embargo, en lugar de contemplar la destrucción de la zona, observamos una serie de imágenes de la resistencia, incluyendo una rescritura de la Estatua de la Libertad sobre la que se filtran los versos finales del poema de Emma Lazarus recitado por Blazkowicz.

El final es voluntariamente ambiguo y genera un margen con respecto a la posición del narrador que, a su vez, abre la posibilidad de continuar con nuevas entregas de la saga: ¿Desde dónde se dirige Blazkowicz al videojugador: desde un hipotético "más allá de la muerte", desde un futuro en el que realmente sobrevive, desde la voluntad del propio Meganarrador? Si bien no tiene gran sentido intentar responder a esta pregunta, sí que resulta extremadamente útil para entender esa concepción de la Historia que venimos esbozando como característica de The new order: en el mundo de los acontecimientos contrafactuales, la posibilidad de proyectar nuestras experiencias hacia el futuro -incluyendo la supervivencia misma de la muerte- es el motor que activa y otorga sentido a la experiencia del texto.

\subsubsection{Gestión del espacio y el tiempo}

Desde un cierto sentido puramente ontológico, todavía no se ha reflexionado lo suficiente sobre las relaciones que se establecen entre tiempo, espacio y videojugador. Algunos autores han intentado realizar una suerte de ontología/epistemología a partir de las posibilidades regladas de los universos virtuales (Mosca, 2011) o de las llamadas "kinesthetic activities" (Karhulahti, 2013). En el caso de The New Order, los parámetros que anclan al avatar en el universo virtual y que permiten su interactuación con el mismo son herederos directos de la tradición del arcade en primera persona: el tiempo real de juego corresponde a un lapso que engloba más de quince años dentro de la ficción, catorce de los cuales se corresponden al estado catatónico del protagonista tras sufrir un aparatoso accidente al final del primer capítulo. La solución que utiliza el Meganarrador para permitirnos transitar ese periodo de tiempo es la única modificación directa sobre nuestra experiencia de lo temporal: una suerte de acelerado en la imagen en la que se suceden los ciclos temporales con algún 
paréntesis puntual para contemplar cómo los soldados nazis secuestran en el Hospital a los enfermos mentales.

Hay, por lo tanto, un tiempo para la acción y un tiempo para la espera. Un tiempo en el que ocurren los acontecimientos (un tiempo Histórico, marcado por la batalla) y un tiempo colapsado en una suerte de paréntesis de no-vida, tiempo vaciado de significación que corresponde, además, con el tiempo de las víctimas, aquellas que el sistema nazi consideraba "vidas indignas de ser vividas" (Colaianni, 2012: 437). Y es interesante, además, que el propio videojuego obligue a la contemplación de los mecanismos de secuestro perpetrados por las tropas nazis, generando una brecha en ese tiempo que fluye a toda velocidad, como si la violencia sistémica redundara en una suerte de quiebra perceptiva, una erosión en la ilusión del continuum que escapa a toda velocidad.

Esta característica está, a su vez, vinculada por la construcción del espacio. El universo de The New Order está escindido en los dos grandes espacios que el jugador puede transitar: los espacios del enemigo (sus laboratorios, prisiones, bases militares...) y los espacios de la resistencia (pequeñas casas polacas, refugios, hangares...). Lo urbano, el flujo político de las ciudades -la hipotética Europa común dominada por los nazis- no existe en el juego más allá de una serie de decorados que se transitan en coche o las conversaciones que se filtran por el sistema del alcantarillado. Del mismo modo, y siguiendo la lógica postmoderna de la que hablábamos anteriormente, el juego combina sin el menor pudor elementos reconocibles (un Londres en el que la arquitectura nazi rodea por completo al Big Ben, paisajes de Berlín o de Norteamérica...) con espacios directamente heredados de la ciencia ficción (bases militares de alta tecnología, laboratorios sumergidos en el océano, colonias en la luna...) El pastiche espacial se construye mediante la superposición de capas simbólicas fácilmente reconocibles por el usuario: la fascinación monumentalista de Albert Speer y la arquitectura utópica del futuro se combinan en un cóctel que, por descabellado que parezca, resulta absolutamente coherente con el proyecto urbanístico nazi. Después de todo: "Es el trabajo que se proponen tanto Speer como Hitler, dejar un legado arquitectónico tal que en su época sea imagen del presente esplendoroso, anuncio de la utopía, y que en un plausible futuro decadente sea la salvación del alma inmortal del Reich" (Sánchez Domínguez, 2011: 203). Los diseñadores de The New Order han tomado al pie de la letra esa posibilidad para generar una experiencia del espacio a medio camino entre la posibilidad de la utopía hitleriana -con referencias directas al Volkshalle, reinterpretado aquí como el London Nautica- y el delirio de las "arquitecturas de la opresión" (B. Jaskot, 1999). Al igual que pasaba con el tiempo, The New Order abre la experiencia de su recorrido al espacio para las víctimas: salas de tortura, fábricas en las que se explota a los esclavos bajo el eufemismo de "trabajos forzados", crematorios en los sótanos de los centros de reclusión... De igual manera que había ocurrido con los primeros Wolfenstein -cuyo diseño icónico estaba directamente inspirado en algunos de los centros de reclusión, especialmente los situados en suelo alemán o austríaco-, aquí podemos encontrar referencias directas a Sachsenhausen (la rampa que conecta los crematorios con el suelo del patio) o a Auschwitz 
I (el rótulo que anuncia la entrada en el campo de Belica tiene el mismo formato metálico y en arco que el tristemente célebre Arbeit macht frei).

Como hemos podido mostrar, tanto la disposición del tiempo como del espacio se conectan de alguna manera con las dos vertientes del proyecto homicida del III Reich: fascinación espacial, mostración temporal, reinterpretación de los acontecimientos históricos. Del mismo modo, se provoca un doblez narrativo y visual que permite comprender las dos caras sobre las que se asienta el fenómeno holocáustico: la mostración de un sistema político apabullante y manipulador frente a la ocultación de sus movimientos homicidas y las deudas contraídas por su política racial. Con estos rasgos clarificados, podemos ya proponer algunas ideas sobre las implicaciones éticas que se desprenden de éstas decisiones.

\subsection{Aspectos éticos}

Más allá de los ya citados debates en torno a la posibilidad de representar el Holocausto, Wolfenstein: The new order resultará pionero como el primer videojuego que hace un uso explícito y constante de los acontecimientos homicidas que tuvieron lugar en Alemania como consecuencia de una política de exclusión y destrucción racial. Si bien es cierto que otros proyectos habían intentado anteriormente aproximarse al Holocausto con fines formativos o incluso paródicos (Rodríguez Serrano, 2011), fracasos recientes como el proyecto de Luc Bernard Imagination is the only escape -que no consiguió el dinero necesario mediante una campaña de crowdfunding- o la polémica que acabó con el proyecto de Sonderkommando Revolt -precisamente, una modificación sobre el código original de Wolfenstein $3 D$ - han demostrado que la polémica entre iconoclastas e iconódulos está muy lejos de quedar zanjada.

Casi al comienzo de The New Order se pone frente al jugador un dilema terrible: debe escoger entre la vida de dos de sus compañeros de escuadrón. Desde la perspectiva puramente narrativa, dicha acción repercutirá en el desarrollo de los acontecimientos que vendrán después y modificará sustancialmente la experiencia del juego. De hecho -y se trata de una opción nada complaciente-, el jugador está obligado a elegir quién debe ser la víctima. No hay posibilidad alguna de zafarse de la elección, de torcer las normas morales improvisadas por los científicos nazis: el pago por recorrer la historia de redención que nos espera es partir de la responsabilidad por una muerte concreta.

Se trata, sin duda, de una potente traducción de los oscuros e incomprensibles meandros que configuraron la particular visión del derecho propuesta por el nacionalsocialismo (García Amado, 1991). A partir de aquí, es necesario comprender que, frente a la triste riqueza de colectivos y casuísticas individuales arrasadas por las políticas homicidas del III Reich, The new order realiza una selección basada únicamente en dos de ellas: los asesinatos eugenésicos y los asesinatos raciales. En las próximas páginas intentaremos ver cómo encara la mostración/reflexión de ambas masacres. 


\subsubsection{Los cuerpos imperfectos: La mostración de las políticas de eugenesia.}

Frente a la gran cantidad de proyectos fílmicos y artísticos que exploran otras características de la barbarie nazi, las políticas de eugenesia siempre se han mantenido en un modesto segundo plano. Si bien intentaron ser legitimadas audiovisualmente en su primera etapa de imposición mediante un notable arsenal propagandístico (Burleigh, 1994), su tratamiento tras la liberación ha quedado en cierta medida menos atendido. Es curioso, a la contra, que The new order realice una amarga mostración de sus acontecimientos por encima incluso de la tragedia del pueblo judío.

La existencia de las políticas de eugenesia aparece citada al menos de tres maneras distintas en el desarrollo argumental. En primer lugar, en los ya citados secuestros que tienen lugar en la clínica en la que reposa Blazkowicz. En segundo lugar, en una trama secundaria de amistad entre un antiguo nazi cuyo hijo fue exterminado por un defecto físico y Max Hass, un discapacitado mental. Por último, en las distintas intervenciones de los distintos villanos nazis. Cada una de ellas está orientada a mostrar tres aspectos distintos de los programas homicidas: la ocultación con la que se desarrollaron y la complicidad de los médicos implicados en el proceso (Holgado, 2012), las implicaciones éticas sobre la sociedad alemana que apoyaba de manera explícita al III Reich (Aly, 2014) y la relación de la misma con una ideología muy anterior al surgimiento de los programas de la Aktion T4.

Ciertamente, el primer problema ético que propone The new order es la duda razonable de si el uso de esas tres líneas de desarrollo se limita a la apropiación narrativa (esto es, convertir la eugenesia nazi en una suerte de "operador textual"), o si por el contrario, propone una posición ética desde la que contemplar los acontecimientos. Como ya hemos señalado anteriormente, hay una torsión formal en el uso del tiempo que parece sugerir la segunda opción. La eugenesia no forma parte de las motivaciones iniciales de la lucha: en Blazkowicz: simplemente emerge de manera paulatina precisamente en el momento en el que él mismo se convierte en colectivo de riesgo. Sin duda, hay algo estremecedor en la decisión que toman los programadores de dejar al jugador literalmente paralizado durante varios minutos, condenado a observar cómo el mundo se despliega a su alrededor mientras los cuerpos no deseados para el sistema desaparecen. El problema de la identidad -ese ¿quién soy? que se formula silenciosamente en cada avatar virtual- se convierte aquí en problema histórico: soy el que observa. La empatía con la víctima está completamente bloqueada: nosotros miramos en silencio los actos de violencia, que ocurren más allá de nuestro control. Si bien uno de los grandes peligros de los videojuegos que se apoyan en la historia contrafactual es sugerir mediante una retórica perversa que los acontecimientos pueden ser "reescritos", The New Order es claro en sus postulados: los cuerpos murieron -aquellos a los que se representa simbólicamente en los enfermos que se conjuran virtualmente ante nosotros, enfermos sin nombre y sin más estatuto que su propio borrado por discapacidades mentales- precisamente porque la Historia no legó ningún Blazkowicz real, ninguna figura heroica definitiva. 
Y frente a los cuerpos sin nombre se presenta la presencia herida de los miembros de la resistencia. Es interesante que casi todos los compañeros que ayudan a Blazkowicz a completar su misión tengan algún tipo de discapacidad física (parálisis en las piernas, el rostro desfigurado) o mental (trastornos de la personalidad, angustia...) Aquellos que componen el "círculo de Kreslau" se presentan como personajes imperfectos, heridos, cuerpos incómodos para la hipotética perfección exigida por los nazis. Por un lado, encontramos el código homogéneo que se proclama en la representación del ejército nazi: soldados uniformemente creados -muchos de ellos sin ni siquiera rostro- o pesadillas robóticas que encarnan la barbarie técnica y genética (Navarro, 2011: 22). Contra ellos se despliega la riqueza de la imperfección, la coherencia de una unión en la que el motor de la emancipación no es un programa ideológico, sino precisamente la aceptación de las heridas.

\subsubsection{El exterminio racial}

The new order, al contrario que otros juegos vinculados con la II Guerra Mundial, incorpora elementos relacionados con el exterminio, tanto mediante técnicas de trabajo forzado como en su vertiente puramente técnica mediante el uso de cámaras de gas. Del mismo modo, genera referencias icónicas que apuntan a diferentes momentos del proceso de tránsito desde las ciudades de los ciudadanos judíos y polacos hasta los lagers. Hay, no obstante, un matiz necesario para entender sus decisiones representativas: la presencia de las cámaras de gas queda siempre elidida de la visión, o bien señalada por los comentarios de otros personajes (el avatar de Hendrix afirma que, en la lógica contrafactual, las cámaras de gas son exportadas a Estados Unidos y jaleadas por los partidarios de la teoría racial), o bien únicamente sugerida por algún tipo de elemento simbólico insertado en la escenografía. Así, por ejemplo, en los exteriores del campo de concentración el jugador puede observar cómo junto a los barracones se han dispuesto varios edificios sin labor aparente, cada uno coronado por varias chimeneas que no dejan de expulsar humo.

El mecanismo expresivo de The new order se basa, por lo tanto, en la creación de un significante vacío en torno al que orbita el resto de acontecimientos. La estrategia, directamente heredada de los límites éticos propuestos por diferentes representaciones fílmicas (Peñalver, 2008), genera una suerte de agujero negro simbólico que marca el límite de lo decible y de lo insertable en la diégesis del universo. La aproximación es tangencial, a partir de la fuerza del testimonio o del arañazo visual, introduciendo una suerte de presencia abrasiva que genera una tensión en los mecanismos de la enunciación.

Dicho con otras palabras: los programadores deciden levantar su discurso a partir de la tensión que se establece entre los dos tipos de Lagers alemanes (concentración y exterminio), creando en su lugar una suerte de "significante campo" -el ya citado Belica- que sirve a su vez como significante total de las políticas de deportación y asesinato nazis. Incapaces de retratar esa potencia total que encierra el "significante Auschwitz", los programadores traducen en términos lúdicos una suma de capas de significación que sirven, a su vez, como extraños ecos de nuestra experiencia visual 
de los campos. Así, además del ya citado letrero metálico que corona la entrada al complejo, encontramos otros pasajes reconocibles. El capítulo se abre con una cinemática en la que se narra la llegada de un convoy al campo. Desde la perspectiva de Blazkowicz, mediante un único plano, observamos cómo se abren las puertas y los cuerpos aterrorizados descienden la rampa. La guardiana del campo -un nuevo trasunto de la Ilsa cinematográfica y de las guardianas femeninas (G. Álvarez, 2012)golpea a los recién llegados. La "llegada" queda conjurada desde el poder de deshumanización que tiene en la literatura de los supervivientes, incluyendo el tatuaje del número y el desconocimiento de las normas del campo. Los "rituales de iniciación" (Moreno Feliu, 2010) quedan esbozados, aunque sea muy brevemente, como una parte fundamental de la experiencia del protagonista.

Algo similar ocurre con otras dos figuras icónicas de los campos: la disposición espacial (Dwork y Jan van Pelt, 2002) basada en las técnicas de Bentham y acotada por alambre de espino y la construcción visual del interior de los barracones, directamente planteada como aparece en las fotografías de Buchenwald tomadas por Margaret Bourke-White. Una vez más, el juego nos plantea la duda de si la citación de dichos elementos responde únicamente a una cuestión de referencia postmoderna o a una cierta invitación para mirar desde otra perspectiva.

En este caso concreto, y a la contra de lo que proponíamos en torno a las políticas de eugenesia, la citación de elementos constitutivos del horror nazi queda lamentablemente desdibujada. La experiencia traumática de la deportación y el proceso de deshumanización son rápidamente sorteadas en apenas diez minutos de juego, mientras que la exploración de la psicología interior de los reclusos no queda esbozada en ningún momento. Las ejecuciones quedan sorteadas mediante las viejas técnicas de "salvación en el último momento" y la introducción de personajes judíos en la trama no aporta ningún tipo de especificidad ni de aprendizaje en torno a problemas holocáusticos básicos como la naturaleza de los verdugos alemanes (R. Browning, 2002; Steinfeldt, 2009) o los rudimentos de la psicología concentracionaria (Todorov, 1993).

Quizá sea demasiado pronto para exigir a un videojuego que pueda hacerse cargo de semejantes problemas. De momento, baste con señalar que la gran aportación de The new order ha sido, frente a todo pronóstico, la posibilidad misma de formular de manera interactiva algunas de las experiencias básicas del exterminio. A su intento se le pueden señalar algunos problemas (la instrumentalización directa de los acontecimientos, la colisión con elementos menos elevados de otros géneros como la ciencia ficción, la falta de profundidad en los planteamientos narrativos y formales), pero también se debe reseñar su valor a la hora simplemente de enunciar mediante un videojuego la existencia de una problemática expresiva y de sus posibilidades. 


\section{Conclusiones}

Al final de nuestro apartado metodológico proponíamos seguir las indicaciones de Rancière en la posibilidad de pensar la "irrepresentabilidad relativa", la "adaptación a los medios", y a los "fines de la representación". Recuperamos ahora esa triple división para acotar algunas de las ideas principales que hemos intentado proponer.

The new order es consciente de las barreras impuestas por los límites de su propia naturaleza virtual. En lugar de proponer un juego que ofrezca una imposible empatía con las víctimas de la tragedia, genera un universo a partir de la historia contrafactual, coherente con las características del sistema de representación postmoderno para que le sirva como punto de partida hacia una reflexión a posteriori sobre el Holocausto.

En segundo lugar, utiliza elementos propios de su lenguaje para proponer un nuevo acercamiento: uso de escenas cinemáticas, gestión del tiempo y el espacio con importantes connotaciones simbólicas propias del videojuego, herramientas derivadas de la interactividad y de la gestión del punto de vista...

Por último, y pese a los problemas que plantea en la mostración de la experiencia de los campos, Wolfenstein: The new order pone sobre la mesa los rasgos principales del proyecto ideológico nazi, incluyendo aquellos que implican una lectura más compleja como los proyectos de eugenesia o el exterminio por motivos raciales. Ambos temas siguen manteniendo una urgencia innegable en nuestras sociedades y forman parte de las amenazas históricas que acechan tras un mal entendimiento de los procesos de la modernidad (Bauman, 1997).

\section{Referencias bibliográficas}

A. PAUL, C. (2012): Wordplay and the Discourse of Videogames: Analyzing words, design and Play. New Jersey: Rutgers University Press.

AGAMBEN, G. (2005): Giorgio, Lo que queda de Auschwitz. El archivo y el testigo: Homo Sacer III. Valencia: Pre-Textos.

ALY, G. (2014): Los que sobraban. Historia de la eutanasia social en la Alemania nazi, 1939-1945. Barcelona: Editorial Planeta.

APEL, D. (2002): Memory Effects: The Holocaust and the art of secondary witnessing. New Jersey: Rutgers University Press.

B. JASKOT, P. (1999): The architecture of Oppression: The SS, Forced Labor and the Nazi Monumental Building Economy. New Jersey: Rutgers University Press.

BAUER, Y. (2002): Rethinking the Holocaust. New Haven: Yale University Press.

BAUMAN, Z. (1997): Modernidad y Holocausto. Madrid: Editoral Sequitor.

BENNETT, J. (2005): Emphatic Vision: Affect, Trauma and Contemporary Art. California: Stanford University Press.

BOGOST, I. (2007): Persuasive Games: The Expressive Power of Video Games. London: The MIT Press. 
BURLEIGH, M. (1994): Death and deliverance. "Euthanasia" in Germany 19001945. Cambridge: Cambridge University Press.

CALABRESE, O. (2012): La era neobarroca. Madrid: Cátedra.

CLARKE, A. y MITCHELL, G. (2007): Videogames and art. Chicago: Intellect books.

COLAIANNI, A. (2012): A long shadow: Nazi doctors, moral vulnerability and contemporary medical culture. Journal of Medical Ethics, 38: 435-438.

DELGADO, A. y GRANADOS, F. (2012): Videojuegos trasladados al cine: análisis y caracterización de la narrativa audiovisual en ambos medios. Revista Comunicación, 10: 63-77.

DWORK, D. y JAN VAN PELT, R. (2002): Auschwitz. Nueva York: W. W. Norton \& Company.

EGENFELDT-NIELSEN, S. , HEIDE, J. Y PAJARES, S. (2013): Understanding Videogames. The Essential Introduction. New Jersey: Rutgers University Press.

DIDI-HUBERMAN, G. (2013): Cuando las imágenes tocan lo real en AAVV, Cuando las imágenes tocan lo real. Madrid: Círculo de Bellas Artes, 8-36.

E. DILL, K. y C. DILL, J. (1998): Video game violence: A review of the empirical literature. Agression and Violent Behavior Journal, 3: 407-428.

FINKELSTEIN, N. (2014): La industria del Holocausto. Madrid: Akal.

FISHER, S. (2011): Playing with World War II: A small-scale study of Learning in Video Games. Loading... Journal, 5: 71-89.

FRASCA, G. (2006): Ephemeral Games: Is it barbaric to design video games after Auschwitz? Cybertext Yearbook 2000, 2: 172-180.

FRASCA, G. (2009): Juego, videojuego y creación de sentido. Una introducción. Revista Comunicación, 7: 37-44.

G. ÁlVAREZ, M. (2012): Guardianas Nazis: El lado femenino del mal. Madrid: Editorial EDAF.

GARCÍA AMADO, J. A. (1991): Nazismo, derecho y filosofía del derecho. Anuario de Filosofía del Derecho, VIII: 341-366.

GÓMEZ TARÍN, F. J. (2012): Formatos y estrategias narrativas híbridas: el cine y la escena cinemática (cut-scenes) en los videojuegos. Interdependencias múltiples en la era digital en Actas del III Congreso Internacional de la AE-IC Comunicación y Riesgo.

GÓMEZ TARIN, F. J. , RUBIO ALCOVER, A. y SAMIT, A. (2012): Punto de vista $y$ videojuegos. Un acercamiento multidisciplinar en Actas del IV Congreso Internacional Latina de Comunicación.

GONZÁLEZ, J. , GUTIÉRREZ, F., MONTERO, F. y PADILLA-ZEA, N. (2012): Playability: analysing user experience in Video Games. Behaviour \& Information Technology, 31: 1033-1054.

GONZÁLEZ-GONZÁLEZ, C. y BLANCO-IZQUIERDO, F. (2012): Designing social videogames for educational uses. Computers \& Education, 58: 250-262.

GONZÁLEZ HORTIGÜELA, T. (2009): Aproximación a la problemática de la enunciación: el lugar del sujeto en el texto artístico. Revista Zer de estudios de Comunicación, 14: 149-163. 
HIRSCH, M. (2001): Surviving Images: Holocaust Photographs and the Work of Postmemory. The Yale Journal of Criticism, 14: 5-37.

HIRSCH, M. (2008): The generation of Postmemory. Poetics Today, 29: 103-128.

HOLGADO, C. (2012): El programa eugenésico nazi: Los programas de eutanasia de la política nazi. Munich: Grin.

J. BROWN, H. (2008): Videogames and Education. Nueva York: M. E. Sharpe.

K. DICK, P. (2010): El hombre en el castillo. Barcelona: Ediciones Minotauro.

KARHULAHTI, V. (2013): A Kinesthetic theory of videogames: Time-Critical Challenge and Aporetic Rhematic. Game Studies: The international journal of computer game research, 13: 1-9.

L. CARNAGEY, N. y A. ANDERSON, C. (2004): Violent video game exposure and aggression: A literature review. Minerva Psichiatrica, 45: 1-18.

MORENO FELIU, P. (2010): En el corazón de la zona gris. Una lectura etnográfica de los campos de Auschwitz. Madrid: Trotta.

MOSCA, I. (2011): Just a cyberplace. The rules in videogames: Between ontology and epistemology. Proceedings of DiGRA, 11: 1-18.

NAVARRO, D. (2011): El programa de Eutanasia de Hitler: Lógica cientifica y la regulación legal de lo atroz. Intertemas, 14: 18-34.

P. BARLETT, C., J. BARLETT, C., J. HARRIS, R. y BALDASSARO, R. (2007): Longer you play, the more hostile you fear: Examination of First Person Shooter Video Games and aggression during video game play. Aggressive Behaviour Journal, 33: 486-497.

PEÑALVER, P. (2008): Del silencio de Auschwitz a los silencios de la historia en VVAA (Coord. REYES MATE): La filosofia después del Holocausto, Barcelona: Riopiedras.

R. BROWNING, C. (2002): Aquellos hombres grises. El batallón 101 y la Solución Final en Polonia. Barcelona: Edhasa.

R. WATSON, W. J. MONG, C. y A. HARRIS, C. (2011): A case study of the in-class use of a video game for teaching high school history. Computers \& Education, 56: 466-474.

RANCIÈRE, J. (2011): El destino de las imágenes. Pontevedra: Politopías.

REYES MATE (2003): Por los campos de exterminio. Barcelona: Anthropos.

RODRÍGUEZ SERRANO, A. (2011): Nuevas formas audiovisuales de la representación del Holocausto. Lenguajes postmodernos para la construcción de la memoria. Revista Prisma Social, 6: 6-22.

RODRÍGUEZ SERRANO, A. (2013): La muerte que habla. La escritura del Holocausto en La zona gris. Revista Trama\&Fondo, 35: 103-116.

RODRÍGUEZ SERRANO, A. (2014): Holocausto, nazismo y videojuegos: Análisis de Wolfenstein (Raven Software, 2009). Vivat Academia, 127: 83-102.

SÁNCHEZ-BIOSCA, V. (2001): Representar lo irrepresentable. De los abusos de la retórica en VVAA, Decir, contar, pensar la guerra (Coord. J BENET, V. y SÁNCHEZ-BIOSCA, V.). Valencia: Subsecretaría de Promoción Cultural.

SÁNCHEZ-ESCALONILLA, A. (2009): Fantasía de aventuras. La exploración de universos fantásticos en literatura y cine. Comunicación y Sociedad, 22: 109-137. 
SÁNCHEZ DOMÍNGUEZ, A. (2011): Arquitectura y prospectividad en los fascismos. Ciencia ficción como punto de partida, utopía como futuro, distopía como destino. Ángulo Recto: Revista de Estudios de la ciudad como espacio plural, 3: 195-204.

SIABRA. J. A. (2012): Bosquejo de una metafisica del videojuego. Madrid: Editorial Círculo Rojo.

SQUIRE, K. (2006): From content to context: Videogames as designed experience. Educational Researcher, 35: 19-29.

STEINFELDT, I. (2009): ¿Cómo fue humanamente posible? Un estudio de perpetradores y espectadores durante el Holocausto. Israel: Yad Vashem.

TAVINOR, G. (2009): The Art of Videogames. Madden: Wiley-Blackwell.

TODOROV, T. (1993): Frente al límite. México: Siglo XXI Editores.

WAJCMAN, G. (2001): El objeto del siglo. Buenos Aires: Amorrortu.

WIESEL, E. (1985): Against Silence. The voice and vision of Elie Wiesel. Nueva York: Holocaust Library.

ZAGAL, J. (2009): Ethically Notable Videogames: Moral dilemmas and Gameplay. Proceedings of DiGRA, 9: 1-9.

ZUMALDE, I. (2011): La experiencia filmica: cine, pensamiento y emoción. Madrid: Cátedra.

\section{El autor}

Aarón Rodríguez Serrano es licenciado y doctor en Comunicación Audiovisual por la Universidad Europea de Madrid y Profesor Titular de la Universidad Europea de Valencia. Máster en Historia y Estética de la Cinematografía (Universidad de Valladolid), Máster en Nuevas Tendencias y Procesos de Innovación en Comunicación (Universitat Jaume I - Castellón). Miembro de la Asociación Española de Historiadores del Cine y de la Asociación Trama\&Fondo. Ha escrito varios libros, entre los que se incluyen Un fantasma recorre la pantalla: cine y sujeto postmoderno (El Genio Maligno, 2011) y Apocalipsis pop! El cine de las sociedades del malestar (Ed. Notorius, 2012). 